\title{
Carbon footprint of air travel to international radiology conferences: FOMO?
}

\author{
${\text { Derya } \text { Yakar }^{1} \text { (D) } \cdot \text { Thomas C. Kwee }}^{1}$
}

Received: 4 April 2020 /Revised: 26 April 2020 / Accepted: 27 May 2020 / Published online: 10 June 2020

(C) European Society of Radiology 2020

The inconvenient truth is that climate change is no longer an activists' subject only. As scientists and medical professionals, it is our duty to promote and protect health. The successes that we have booked in the development of global health over the last decades are now under threat due to climate change. Paradoxically enough, as promoters of health, we are part of the problem.

Airplane travel is among the most polluting activities, and it is estimated that, considering the growth in demand, aviation will make up $22 \%$ of the global carbon budget [1]. Many scientists and medical professionals may be among the most frequent flyers due to traveling to international meetings [2]. The purpose of flying to these scientific meetings is plural and includes the opportunity to meet international colleagues for collaboration, present new scientific results, listen to highly renowned expert lecturers, or check out new medical imaging technologies. International conventions such as the RSNA and the ECR have been offering more online lectures and materials in the last couple of years. Despite the online availability of such materials, professionals in the field still attend these physical meetings in large numbers. Understanding why we all massively prefer being present is key to lowering the carbon footprint of these meetings. Furthermore, the fear of missing out (FOMO) is also a frequently heard reason to attend international conferences. Missing opportunities to collaborate or network for research purposes, publishing less frequently or in less high-impact journals, and diminished visibility are among these feared reasons [3]. In a recent study [4], the investigators have examined whether academic air travel has an influence on professional success. In a sample of 705

Derya Yakar

d.yakar@umcg.nl

1 Medical Imaging Center, Department of Radiology, Nuclear Medicine and Molecular Imaging, University Medical Center Groningen, University of Groningen, Hanzeplein 1, P.O. Box 30.001, 9700 RB Groningen, The Netherlands travelers, they investigated the influence of research productivity and other variables on academic air travel and the associated emissions. They found no relationship between air travel emissions and metrics of academic productivity including hIa (h-index adjusted for academic age and discipline) [4]. This is good news; it means that we can maintain a successful academic career while reducing our carbon footprint at the same time. Nonetheless, many would argue that corporeal proximity is essential for purposes such as international networking or maintaining interactivity during a workshop or training. However, we seriously need to ask ourselves at what cost? If by our actions we contribute, even in a very indirect manner, to undernutrition, malaria, coastal floods, diarrhea, heat stress, and dengue [5], we urgently need to change the way we think and behave.

There is no single measure that will be successful on its own; instead, we have to think of multiple measures that we can take in reducing carbon dioxide emissions. Offsetting our air travel-related carbon footprint is cost-effective [5] and the radiological society could undertake steps to do this. Academic societies might choose to add the costs of offsetting to the meeting's fees. However, a more direct approach is to reduce the carbon footprint itself. In a 2012 [6] study, it was stated that the carbon emission of a conference is essentially related to one single variable, namely how far participants travel to reach the venue. Interestingly, distance does not deter one to flying to long overhaul travels since expenses are usually covered by institutions or sponsors [7]. Therefore, Orsi [6] concluded that decentralization of a conference could have substantial effects on reducing carbon emissions. Pay attention, that particular study is not defending replacing a singlevenue with a multi-venue conference. The author warns that by increasing accessibility, this might create the opposite effect of an increased number of applicants. Instead, it should be announced as a single-venue event, and after application depending on number and origin of participants, different venues should be added. This seems like a very interesting option to consider. Another additional measure we can take to cut back 
carbon dioxide emissions could be to reduce the frequency of these meetings to once every two years or sending fewer members [8]. We already know that video conferencing is a good aid and that it is able to spread knowledge and create new ideas. However, during the recent coronavirus lockdown, we have also experienced that videoconferencing needs to be more fine-tuned from a technical point of view (interactivity may become compromised) as well as following etiquette by users (e.g., don't forget to mute yourself when not speaking). Perhaps new videoconferencing technologies or software will address these limitations. Simpler steps such as reducing energy spill (lightning, left on monitors, air conditioning systems, recycling congress material) are worth considering and should be done. However, we know they are not the most polluting and that they should not distract from the most important problem, namely aviation [9].

If we, as individuals, should take matters into own hand, behavior changes are unlikely to come if collective habits are not changed either.

If the international crisis caused by the new coronavirus has taught us one thing, then it is societies' ability to act fast and rigorously when convinced of the seriousness of a situation. Given the fact that we already made small steps towards more climate friendlier conventions with more online materials, it means we can and want to address the issue of climate change. On an organizational level, it requires creativity to renew these international meetings while minimizing negative economic consequences. We as radiologists can choose to be part of the solution; it is time we step up the pace of renewal soon rather than tackling the issue of climate change too late.

Funding information The authors state that this work has not received any funding.

\section{Compliance with ethical standards}

Guarantor The scientific guarantor of this publication is Derya Yakar, $\mathrm{MD}, \mathrm{PhD}$.

Conflict of interest The authors of this manuscript declare no relationships with any companies whose products or services may be related to the subject matter of the article.

Statistics and biometry No complex statistical methods were necessary for this paper.

Informed consent Written informed consent was not required for this study.
Ethical approval Institutional Review Board approval was not required.

Methodology NA

\section{References}

1. Cames M, Graichen J, Siemons A, Cook V (2015) Emission reduction targets for international aviation and shipping. Policy Department A: Economic and Scientific Policy, European Parliament, B-1047 Brussels

2. UNWTO (2017) UNWTO tourism highlights: 2017 edition. World tourism organization, Madrid

3. Storme T, Beaverstock JV, Derrudder B, Faulconbridge JR, Witlox F (2013) How to cope with mobility expectations in academia: individual travel strategies of tenured academics at Ghent University, Flanders. Res Transp Bus Manag 9:12e20

4. Wynes S, Donner SD, Tannason S, Nabors N (2019) Academic air travel has a limited influence on professional success. J Clean Prod 226:959e967

5. Yakar D, Kwee TC (2020) Carbon footprint of the RSNA annual meeting. Eur J Radiol 125:108869

6. Orsi F (2012) Cutting the carbon emission of international conferences: is decentralization an option? J Transp Geogr 24:462-466

7. Black WR (2001) An unpopular essay on transportation. J Transp Geogr 9:1-11

8. Nathans J, Sterling P (2016) How scientists can reduce their carbon footprint. Elife 5:e15928

9. Gössling S, Broderick J, Upham P et al (2007) Voluntary carbon offsetting schemes for aviation: efficiency, credibility and sustainable tourism. J Sustain Tour 15:223-248

10. Attari SZ, Krantz DH, Weber EU (2016) Statements about climate researchers' carbon footprints affect their credibility and the impact of their advice. Clim Change 138:325e338

We are well aware that the size of our own carbon footprint affects the credibility of this editorial [10]. Therefore, we disclose the following information: In 2016 and 2017, Yakar attended the EANM (European Association of Nuclear Medicine) in Barcelona and Vienna respectively, both by plane. In 2018, Yakar traveled by plane to the SCBT-MR (Society of Computed Body Tomography \& Magnetic Resonance) (Washington DC, USA) and the RSNA (Radiological Society of North America) (Chicago, USA). In 2019, Yakar attended the ESGAR (European Society of Gastrointestinal and Abdominal Radiology) (Rome, Italy) by plane. In 2018, Kwee traveled by plane to the Stoller MSK course (New York, USA). In 2019, Kwee attended the Advanced MRI course (Graz, Austria) by plane.

Publisher's note Springer Nature remains neutral with regard to jurisdictional claims in published maps and institutional affiliations. 